\title{
A natural history study of the prognostic role of coronary arteriography
}

James F. Brymer, M.D.

Thomas H. Buter, B.A.

Joseph A. Walton, Jr., M.D.

Park W. Willis, III, M.D.

Ann Arbor, Mich.

As surgical operations are more widely applied in the treatment of coronary heart disease, continued development of guidelines for the selection of patients for surgery is needed. Operative mortality and morbidity rates remain significant in many centers. The distribution and extent of coronary artery atherosclerosis and left ventricular function are thought to influence the surgical risk. Knowledge of the influence of these factors on the outcome in patients managed medically is needed, so that operative risks and results can be seen in perspective and so that patients and physicians can compare the relative merits and expected outcome of medical and combined medical-surgical treatment. There are several recent contributions ${ }^{1-5}$ reporting the natural history of arteriographically demonstrated and graded coronary occlusive disease. Few of the series are large, however, and only two reflect a follow-up of five years or more. ${ }^{1,5}$ The object of the present report is to add to the gradually accumulating body of data in this area. Record of patients who underwent coronary arteriography at the University of Michigan teaching hospitals were collected and the natural history of their disease to date is presented with emphasis on the prognostic value of the knowledge of the extent of lesions, the presence

From the Section of Cardiology, Department of Internal Medicine, University of Michigan Medical Center, Ann Arbor, Mich.

Supported in part by the Michigan Heart Association. Mr. Buter was a 1972 recipient of a Michigan Heart Association medical student research scholarship.

Received for publication Aug. 1, 1973.

Reprint requests to: Park W. Willis, III, M.D., Director, Section of Cardiology, University of Michigan Medical Center, Ann Arbor, Mich. 48104. of prior myocardial infarction, and the effect of left ventricular dysfunction.

\section{Materials and methods}

Coronary cinearteriograms and clinical records of 175 patients studied at the University of Michigan Hospital and the Ann Arbor Veterans Administration Hospital from January, 1965, through June, 1972, were reviewed. The 129 patients studied at Wayne County General Hospital, Eloise, Mich., between July, 1968, and December, 1970, were subsequently added to the review. The 1970 cut-off date was used in the latter group to assure at least two years' follow-up in those patients. All studies that were technically inadequate to allow grading of all major coronary branches were excluded. Also excluded were patients with valvular or primarily muscular heart disease.

An attempt was made to correlate the character of clinical symptoms with the arteriographic appearance of the coronary arteries. Angina pectoris was strictly defined (Table I) as visceral pain, involving at least some part of the sternum; precipitated by effort, emotion, cold exposure, or heavy meals; lasting not longer than 20 minutes after cessation of activity; and usually promptly relieved by nitroglycerin. Pain syndromes that did not meet all these criteria were called atypical. We did not attempt to subdivide the atypical syndromes because, often, the recorded histories were not sufficiently detailed to allow precise distinction between probable cardiac and noncardiac pain. A few patients were included who did not complain of pain but had other evidence - usually an abnormal electrocar- 
Table I. Criteria used to identify typical angina pectoris

1. Must involve some part of the sternum

2. Must be precipitated by exertion, emotion, cold exposure, heavy meals

3. Must be visceral pain-i.e., squeezing, burning, tightness

4. Must not last longer than 20 minutes after cessation of activity

5. Should be relieved promptly by nitroglycerin

Table II. Arteriographic scoring system*

\begin{tabular}{|c|c|}
\hline Points & Degree of obstruction \\
\hline 0 & No abnormality seen \\
\hline 1 & Trivial irregularity in lumen diameter \\
\hline 2 & $\begin{array}{l}\text { Localized area of narrowing - greater than } 50 \text { per } \\
\text { cent, less than } 90 \text { per cent }\end{array}$ \\
\hline 3 & $\begin{array}{l}\text { Multiple areas of narrowing in the same vessel- } \\
50 \text { to } 90 \text { per cent }\end{array}$ \\
\hline 4 & Narrowing greater than 90 per cent \\
\hline 5 & Complete obstruction \\
\hline
\end{tabular}

*After Friesinger and associates. 1

Table III. Comparison of clinical symptoms with arteriogram score

\begin{tabular}{|c|c|c|c|c|}
\hline & \multicolumn{4}{|c|}{ Score } \\
\hline & $0-3^{*}$ & $2-5 t$ & $6-10$ & $11-15$ \\
\hline No chest pain & 2 & 1 & 7 & 2 \\
\hline Typical angina pectoris & 14 & 23 & 88 & 51 \\
\hline Atypical chest pain $\ddagger$ & 79 & 12 & 18 & 6 \\
\hline
\end{tabular}

*No more than a one-point lesion in any vessel.

fAt least a two-point lesion in one vessel.

\#False positives, eight per cent (typical angina pectoris with normal arteriogram); false negatives, 31 per cent (atypical pain with abnormal arteriogram).

diogram (ECG) - suggesting coronary disease.

Coronary cinearteriograms were scored according to the method described by Friesinger, Page, and Ross ${ }^{1}$ (Table II). The right coronary artery (RCA), the left anterior descending (LAD), and left posterior circumflex (LPC) branches were scored individually and the scores added to arrive at the total score for each patient. The maximum possible score thus was 15 points. Lesions of the main left coronary artery were treated as if both LAD and LPC were involved.

Left ventricular cineangiocardiograms were reviewed and graded when these were available. Prior myocardial infarction was diagnosed only when diagnostic QRS changes were present in an electrocardiogram recorded prior to cardiac catheterization.

Follow-up information on the patients was obtained from the hospital records of those patients who attended the cardiac clinic of the participating hospital. The referring physicians of those patients who did not return were contacted by telephone and in some cases the patients were contacted personally by mail or telephone.

\section{Results}

A total of 304 patients was included in the review: 251 were men (ages 18 to 69 , median 47) and 53 were women (ages 28 to 66 , median 46 ).

The patients' presenting symptoms were compared with arteriographic scores. Close correlation was found between typical angina pectoris and serious coronary obstruction by the arteriogram. Ninety-two per cent of the patients with typical angina had at least a two-point lesion (greater than 50 per cent obstruction) in at least one major vessel. Atypical pain was much less specific: 31 per cent of such patients had evidence of serious disease and 69 per cent had normal-appearing arteriograms of minor obstruction (less than 50 per cent occluded) in one or more vessels. Nonspecificity in the latter group was probably related to the wide range of presenting complaints included in the atypical category (Table III).

Eighty-five patients subsequently underwent an operative procedure for coronary heart disease (Vineberg mammary artery implant or saphenous vein aortocoronary bypass grafts) and are not considered further.

Ninety-five patients had relatively normal-appearing coronary arteriograms. Two of these 95 patients died during the follow-up period (2 per cent). Mean follow-up interval for this group of patients was 24 months. One of the patients who died was a 28-year-old black, hypertensive woman who had had repeated episodes of ventricular paroxysmal tachycardia in the hospital. The arrhythmia was associated with bouts of 
chest pain, usually occurring at rest, eventually controlled by bretylium tosylate, and she was maintained on that drug as an outpatient. Her coronary arteries appeared completely normal. She died suddenly at home several months following her study. Aside from the arrhythmia, her ECG had been normal, as was her left ventriculogram. The other patient who died was one of seven patients with relatively normal-appearing coronary arteriograms but ECG evidence of prior myocardial infarction. She was a 56-year-old white woman whose precatheterization ECG showed QRS changes of old anterior myocardial infarction. Nevertheless, her coronary arteriogram was completely normal. She was brought to the hospital, dead on arrival, after she collapsed suddenly at home two days following her arteriography.

There remained a nonoperative group of 124 patients with abnormal coronary arteriograms. For the purposes of this report of natural history only survival of the patients was considered. The follow-up period ranged from just a few months to nearly seven years, with a mean follow-up of 19 months. Of these 124 patients, 21 (17 per cent) died during the follow-up period. Five per cent of these patients have been lost to follow-up.

Among those with mild to moderately severe disease ( 2 to 7 points) the mortality rate was 11 per cent ( 6 of 57 ); 22 per cent (15 of 67 ) of those with severe disease ( 8 to 15 points) died. Among those with single vessel disease the mortality rate was 10 per cent (4 of 41 ); with two- and three vessel disease it was 20 per cent (9 of 44) and 21 per cent ( 8 of 39 ), respectively.

It became apparent that left anterior descending disease was highly prevalent in those who died. Nineteen of 21 ( 90 per cent) patients who died had significant LAD disease. With the data arranged to reflect the influence of LAD involvement, the mortality rate was doubled -14 per cent ( 4 of 28 ) vs. 7 per cent ( 2 of 29 ) - in the mild to moderate disease group (two- to 7-point score) when LAD was involved. Among the severe disease patients ( 8 to 15 points) the mortality rate was nil (none of 13 patients) when LAD was not significantly involved (despite the presence of severe disease in the other major coronary branches). This difference is not statistically significant $(\mathrm{p}=0.08)$.

Using the standard life table methods ${ }^{9}$ Figs. 1

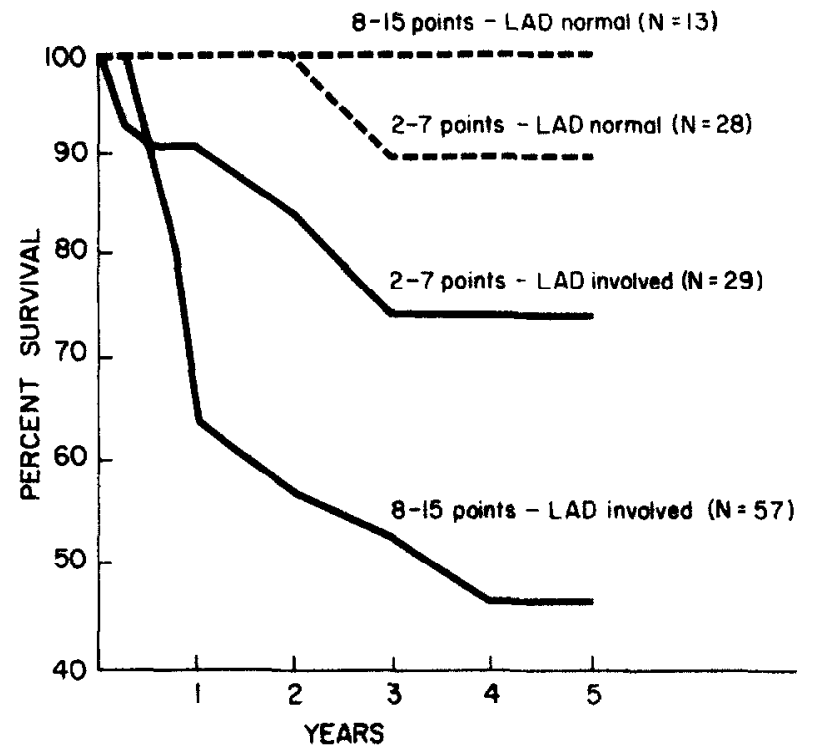

Fig. 1. Survival of nonoperative patients grouped by arteriographic score. Whether LAD was involved is indicated.

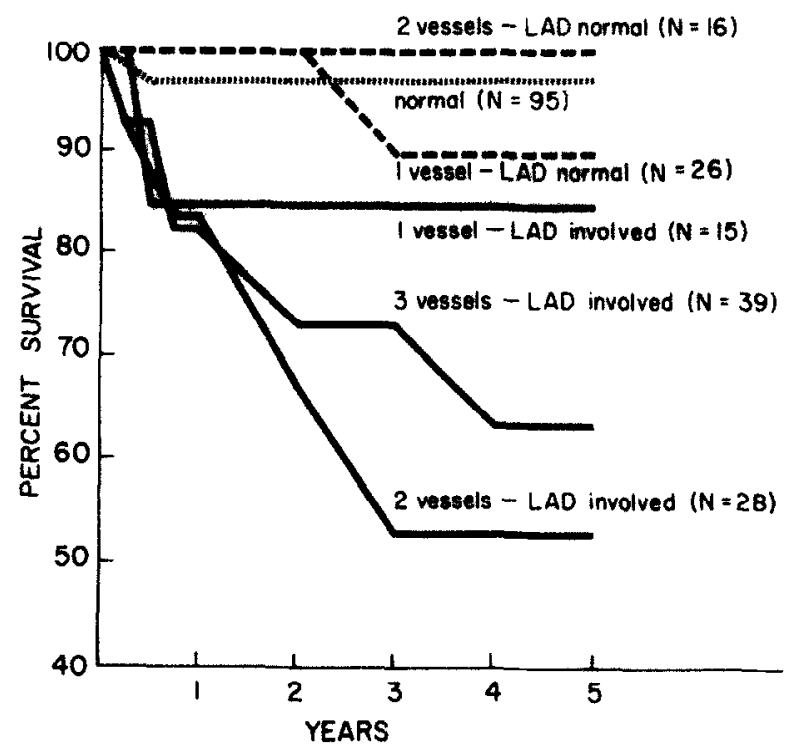

Fig. 2. Survival of nonoperative patients grouped by number of vessels seriously involved. When $L A D$ was involved, this is indicated. Survival of normal subjects is also shown.

and 2 were derived to demonstrate survival results graphically. The latter portion of each curve tends to flatten because of the small number of patients at the later points of follow-up and probably does not accurately reflect prognosis. This applies both to the diagram illustrating survival by total score (Fig. 1) and to Fig. 2 which illustrates the prognosis for normal subjects and for those with one-, two-, and three-vessel disease. 
Seventeen patients had left main coronary artery lesions of greater than $\mathbf{5 0}$ per cent occlusion and eight of these (47 per cent) died within one to 23 months.

Other factors that might influence the outlook in these patients were considered. Those patients with prior history of myocardial infarction and ECG evidence of diagnostic QRS changes incurred a mortality rate of 21 per cent; those without definite evidence of infarction had a mortality rate of only eight per cent. Similarly, and perhaps as an effect of prior infarction, left ventricular dysfunction by cineangiocardiogram was associated with a 26 per cent mortality rate regardless of the degree of coronary artery obstruction, whereas only four per cent of those with apparently normal left ventricular function died. Left ventriculograms were available for review in 90 per cent (111 of 124) of these cases.

\section{Discussion}

In this series of patients we found close correlation of typical angina pectoris, when strictly defined, with arteriographic evidence of serious (greater than 50 per cent) coronary obstruction. Our finding of 92 per cent positive correlation is consistent with previously reported results. 1,6

We found that 98 per cent of patients with normal or less than 50 per cent obstructed coronary arteries survived through the follow-up period. This finding, that normal arteriograms imply a good prognosis regardless of the severity or variety of clinical symptoms, is in agreement with recent reports. ${ }^{1,7,8}$ Similarly, we found evidence confirming other reports ${ }^{1-5}$ indicating that survival of patients with coronary artery disease treated medically or observed without treatment varies directly with the severity of the disease, the number of vessels involved, the presence of prior myocardial infarction, and left ventricular dysfunction.

We found that serious disease in the left anterior descending branch implied, over all, a worse prognosis than a normal-appearing LADwhether it was the only vessel involved or, even more strikingly, when LAD was involved in combination with disease in other vessels. This difference approached statistical significance when the coronary occlusions were high grade $(8$ to 15 point scores by the system used) even though numbers of patients are small and follow- up relatively short. We feel that, although it has been mentioned by others, ${ }^{5}$ the particular influence on the mortality rate of LAD disease has been insufficiently stressed.

We conclude, from these data, that those factors which appear to adversely affect survival in surgically treated patients-namely, severe multiple vessel disease, particularly left main or anterior descending coronary artery disease, and left ventricular dysfunction - play a similar role in patients managed medically or observed without treatment. Conversely, mild coronary disease, the absence of demonstrable prior myocardial infarction, and normal left ventricular contraction, a combination of factors thought to characterize the ideal operative candidate, appear also to portend a low mortality rate and favorable outcome when an operation is not performed.

It remains for continued follow-up of groups of patients such as ours, and of similarly well-documented and followed groups of patients having coronary operations, to demonstrate differences between the groups and answer the question whether the results of operative therapy justify the risks and expense of that mode of treatment.

\section{Summary}

Coronary cinearteriograms, clinical records, and left ventriculograms of 304 patients studied for evaluation of chest pain were reviewed. Clinical and follow-up data on survival of the normal subjects and the nonoperative group with abnormal arteriograms are presented.

Ninety-two per cent of patients with typical angina pectoris had serious coronary occlusive disease. Ninety-eight per cent of patients with relatively normal coronary arteriograms survived for one to 60 or more months (mean followup period 24 months).

There was a high mortality rate when the left main coronary artery was involved ( 47 per cent) and when the left coronary anterior descending branch was seriously occluded ( 28 per cent when arteriographic scores were high and 14 per cent when total scores were low) and a low mortality rate ( 0 to 7 per cent) when the LAD was normal. Mean follow-up interval in these groups was 19 months.

The mortality rate was nearly three times greater when patients had QRS changes on ECG 
of prior myocardial infarction and six times greater when left ventricular contraction was significantly impaired.

\section{REFERENCES}

1. Friesinger, G. C., Page, E. E., and Ross, R. S.: Prognostic significance of coronary arteriography, Trans. Assoc. Am. Physicians 83:78, 1970

2. Oberman, A., Jones, W. B., Riley, C. P., Reeves, T. J., Sheffield, L. T., and Turner, M. E.: Natural history of coronary artery disease, Bull. N. Y. Acad. Med. 48:1109, 1972.

3. Slagle, R. C., Bartel, A. G., Behar, V. S., Peter, R. H., Rosati, R. A., and Kong, Y.: Natural history of angiographically documented coronary artery disease, Circulation 45 (Suppl. II):60, 1972 (abst.).

4. Basta, L. L., and Kioschos, J. M.: Results of medical management of angina pectoris in candidates for saphenous vein bypass graft, Proc. Cent. Soc. Clin. Res. 44:14, 1971 (abst.).

5. Moberg, C. H., Webster, J. S., and Sones, F. M.: Natural history of severe proximal coronary disease as defined by cineangiography (200 patients, 7 year follow-up), Am. J. Cardiol. 29:282, 1972 (abst.).

6. Proudfit, W. L., Shirey, E. K., and Sones, F. M.: Selective cine coronary arteriography, correlation with clinical findings in 100 patients, Circulation 33:901, 1966.

7. Bemiller, C. R., Pepine, C. J., and Rogers, A. K.: Long term observations in patients with angina and normal coronary arteriograms, Circulation 47:36, 1973.

8. Bruschke, A. V. G., Proudfit, W. L., and Sones, F. M.: Clinical course of patients with normal, and slightly or moderately abnormal coronary arteriograms: a follow-up study on 500 patients, Circulation 47:936, 1973.

9. Hill, A. B.: Principles of medical statistics, ed. 7, New York, 1961, Oxford University Press. 